\title{
Peripheral males: A primate model for a human subgroup
}

\author{
JOAN S. LOCKARD \\ University of Washington, Seattle, Washington 98195 \\ and \\ ROBERT M. ADAMS \\ Eastern Kentucky University, Richmond, Kentucky 40475
}

\begin{abstract}
Males are observed in several nonhuman primate species to exhibit a subadult stage not shared by females. While females are gradually integrated into the group upon reaching reproductive age, some older adolescent males remain apart (i.e., peripheral), associating largely with same-sex peers. Evidence regarding an analogous stage in the development of human males 18 to 20 years old was sought by an analysis of the relative frequencies of various age-sex groupings in public. Over 10,000 groups were observed in shopping malls, and the estimated age and sex of each member were recorded. A significantly greater than expected frequency of exclusively subadult male groups (three to four members) was found relative to female or mixed-sex groups of the same age.
\end{abstract}

Studies of nonhuman primate development and social organization, especially in species that are to some degree terrestrial, have repeatedly found behavior patterns characteristic of males that differ from those of females as they progress from juvenile to full adult members of the group. Females seem to negotiate the transition to adulthood more easily than males, who are not typically classified as adults (i.e., socially mature) for a time, in spite of their postpuberty status. Subadult males have been characterized as peripheral (Kummer, 1971), even though they may be allowed to move freely through the group. They have been reported to maintain a physical separation from the focus of their groups in several species, including the mountain gorilla (Harcourt, Steward, \& Fossey, 1976; Schaller, 1963), siamang (Chivers, 1971), langur (Jay, 1965), Japanese macaque (Sugiyama \& Ohsawa, 1974), and baboon (Hall \& Devore, 1965). In addition to physical separation, these males often predominantly associate with other same-age males as "bachelor groups" (Cohen, 1971; Hrdy, 1977). They are also described by these authors as engaging in exuberant play, as being submissive toward dominant males, and as displaying aggression toward subordinate males.

Casual observations of behavior in public places suggests a human subgroup analogous to the peripheral

This research was completed in part through funding from the Harry Frank Guggenheim Foundation. The programming expertise of Douglas Kalk and the valuable assistance of Barbara Kirkevold, Barbara Boni, and Gordon Naccarato in the conduct of the study are gratefully appreciated. males. The necessary supporting data, however, are of a type that has not been widely sought, and which must be drawn from widely divergent areas. With regard to affiliative behavior, Tiger (1969) has contended that adult same-sex groupings carry greater selective advantage for males than for females. This position receives some support from observations of children's groupings (Maccoby \& Jacklin, 1974) and from a self-report study of Soviet students showing that males of age 14-20 years show a greater preference for same-age and same-sex friends than do females (Kon \& Losenkov, 1978). An example of human behavior that appears analogous to the nonhuman subadult male's voluntary separation is found in Latané and Liane's (1977) observations of college students on campus. Males were more likely to be alone than females, although the sex composition of observed groupings was not reported.

Other relevant information may be drawn from a sociological and anthropological perspective, including later age of marriage in males of nearly all cultures (Presser, 1975), rites of passage into adulthood characteristic of anthropological cultures (Coon, 1971), and the overwhelming maleness of youth gangs (Konner, 1976). In general, it is difficult to think of an aspect of the social system into which males are integrated at an earlier age than females.

The view that emerges from all this is one of males between adolescence and adulthood as a group apart, resembling the subadult males of nonhuman primate species. The present study sought to provide data more directly relevant to this proposed analogy through the use of a demographic approach. Observations were made 
on natural groupings in public, with the prediction of a greater likelihood of all-male groupings in the 18- to 20-year-old age range.

\section{METHOD}

Data were gathered in Seattle, Washington, in two large, enclosed shopping malls in which a demographic cross-section of the city was likely to be seen. Observation times were evenings, 7:00-9:00 p.m., and weekends, 1:00-5:00 p.m., in order to reduce the likelihood of excluding any age-sex groups. The number, up to six, and age-sex classification of every group of persons exiting along a definable path was recorded by three female and two male observers. A total of 11,536 groups were observed, of which 4,574 were appropriate to this study. Prior to the observations, all observers were trained in age estimation by participation in a survey that allowed them to estimate, then ask, the ages of at least 300 persons of varying ages. Mean directional variance at the end of this training was less than 1.5 years for the age group, 12-26 years, under study. Interobserver reliability coefficients at the study site ranged from .75 to $.98(\mathrm{p}<.05)$ for all observer combinations.

\section{RESULTS}

The data were subjected to computer analysis, and the observed frequencies of specified age-sex groupings were compared by chi-square statistics to expected frequencies based on a binomial distribution, the computations for which are given in Table 1. For example, in considering dyadic groups only $(i=j=2)$, the probability of either a female or a male being observed in

Table 1

\footnotetext{
$\mathrm{i}=$ lower limit of group size.

$\mathrm{j} \quad=$ upper limit of group size.

$\mathrm{Gij}=$ observed frequency of groups of size $i$ to $j$ that meet group age category requirement(s).

Gk = observed frequency of groups of size $k, k=i, j$.

$\mathrm{Gij}=\underset{\mathbf{k}=\mathbf{i}}{\mathbf{j}} \mathrm{Gk}$.

$\mathrm{m}=$ number of males in the entire population that meet age category requirement(s).

$\mathrm{f}=$ number of females in the entire population that meet age category requirement(s).

$T=\mathrm{m}+\mathrm{f}$.

$\mathbf{P}_{\mathbf{M}}=\mathrm{m} / \mathrm{T}$.

$P_{F}=\mathbf{f} / \mathbf{T}$.

$\mathrm{Rk}=\mathrm{Gk} / \mathrm{Gij}, \mathrm{k}=\mathrm{i}, \mathrm{j}$ (probability of size $\mathrm{k}$ group in the $\mathrm{Gij}$ groups).
}

Expected coefficients:

$E_{\mathbf{i j}}^{\mathbf{M}}=\underset{\mathbf{k = i}}{\mathbf{j}}\left(\mathbf{P}_{\mathbf{M}}\right)^{\mathbf{k}} \cdot \mathbf{R k}$
$\mathbf{E}_{\mathbf{i j}}^{\mathbf{F}}=\underset{\mathbf{j}=\mathbf{i}}{\mathbf{j}}\left(\mathbf{P}_{\mathbf{F}}\right)^{\mathbf{k}} \cdot \mathbf{R k}$
$\mathbf{E}_{\mathbf{i j}}^{\mathbf{X}}=1-\left(\mathbf{E}_{\mathbf{i j}}^{\mathbf{M}}+\mathbf{E}_{\mathbf{i j}}^{\mathbf{F}}\right)$

(males)

Expected frequency:

$\mathbf{N}_{\mathbf{i j}}^{\mathbf{M}}=\mathbf{E}_{\mathbf{i j}}^{\mathbf{M}} \cdot \mathrm{Gij}$

$\mathrm{N}_{\mathrm{ij}}^{\mathrm{F}}=\mathrm{E}_{\mathrm{ij}}^{\mathrm{F}} \cdot \mathrm{Gij}$

$N_{i j}^{X}=E_{i j}^{X} \cdot G i j$

(females)

(mixed)

(males)

(females)

(mixed)

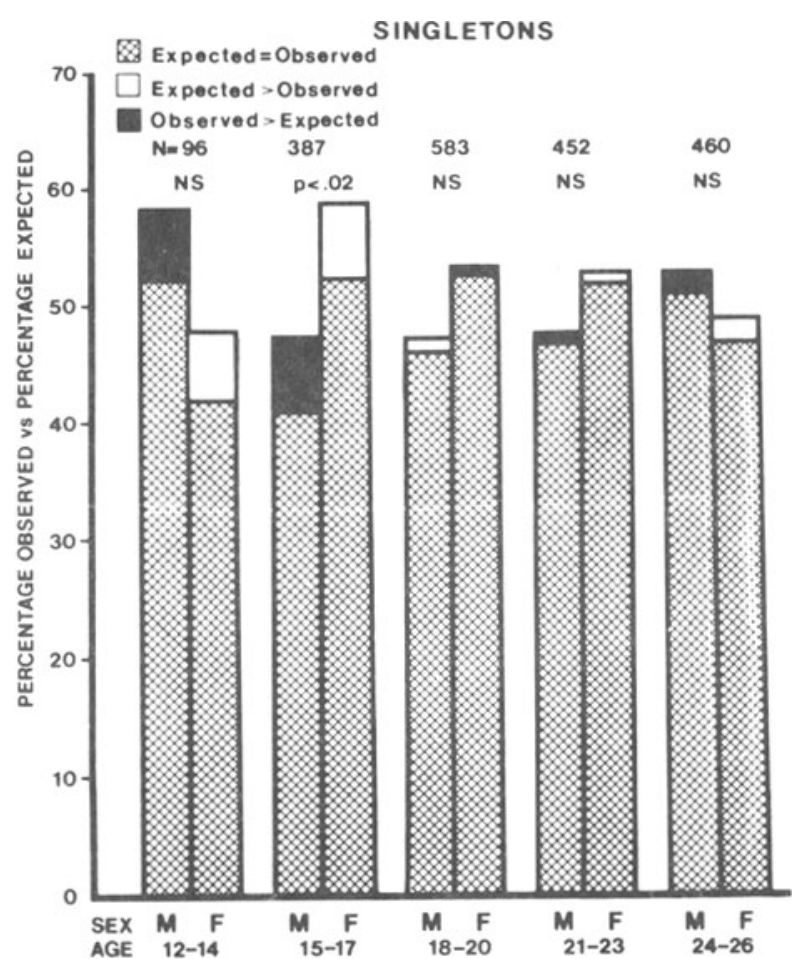

Figure 1. Singletons: Percentage of males and females observed in public vs. percentage expected, based on a binomial distribution, for five age categories. 'The focal category is subadult (18-to-20-year-olds), where single males and females are seen in expected numbers. Statistical significance using chi square is indicated by a probability statement $(p<.02)$; NS = not significant.

public alone is assumed to be .50 and, therefore, $\mathbf{R}_{\mathbf{2}}=1.00$. The expected coefficient for a same-sex dyad would be the product of the probability of a same-sex dyad and the probability of a dyad in general (i.e., $\left..50^{2} \times 1.00=.25\right)$. The expected coefficient of a mixed dyad is obtained simply by subtracting from 1.00 the sum of the expected coefficients of same-sex dyads [i.e., $1.00-(.25+.25)=.5$ ]. The observed frequency of all dyads of a group age category is then multiplied by these expected coefficients to manifest the expected frequencies of occurrence for the same-sex dyads and mixed-sex dyads. In a similar fashion, the expected frequencies for triads $(i=j=3)$, quadrads $(i=j=4)$, and triads and quadrads combined $(i=3, j=4)$ may be computed.

Figure 1 shows the comparison of expected to observed frequencies of single individuals in each age-sex category. Only the 15- to 17-year-olds differed significantly from expected values $\left[\chi^{2}(1)=6.54, p<.02\right]$. Observed frequencies in the subadult, 18- to 20 -year-old category did not differ from chance. Figure 2 reveals significant differences from expected dyadic frequencies in every age category. Same-sex male and female pairs under 21 years old were overrepresented, and mixed-sex pairs were overrepresented in the group of 24- to 26-year-olds. 


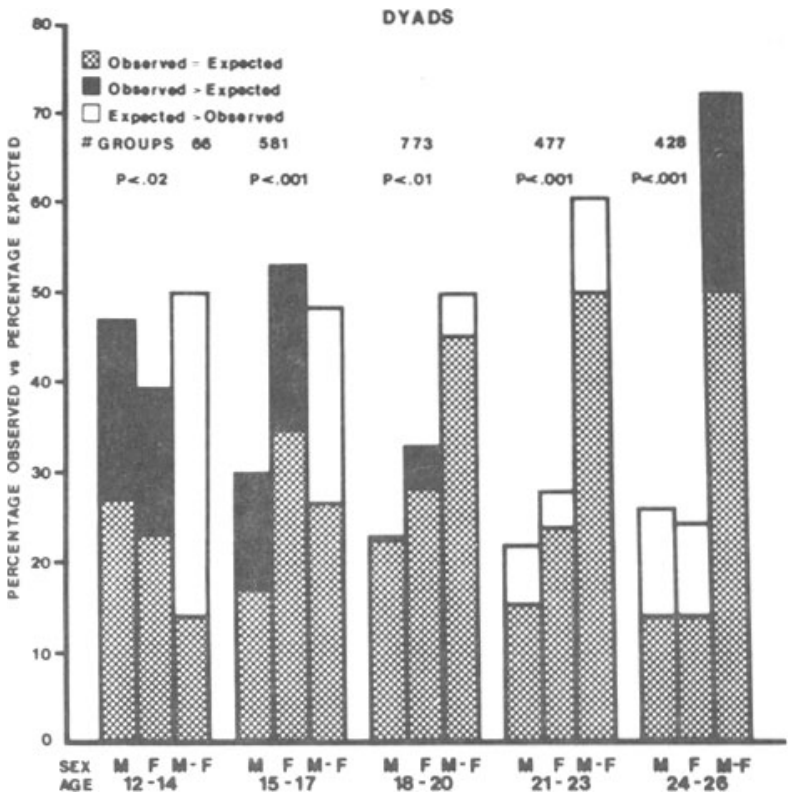

Figure 2. Dyads: Percentage of male, female, and mixed-sex pairs observed in public vs. percentage expected, based on a binomial distribution, for five age categories. The focal category is subadult (18- to 20-year-olds), where an expected number of same-sex male dyads are seen, compared with same-sex females and mixed-sex pairs. Statistical significance using chi square is indicated by a probability statement (e.g., $\mathrm{p}<.02$ ); NS = not significant.

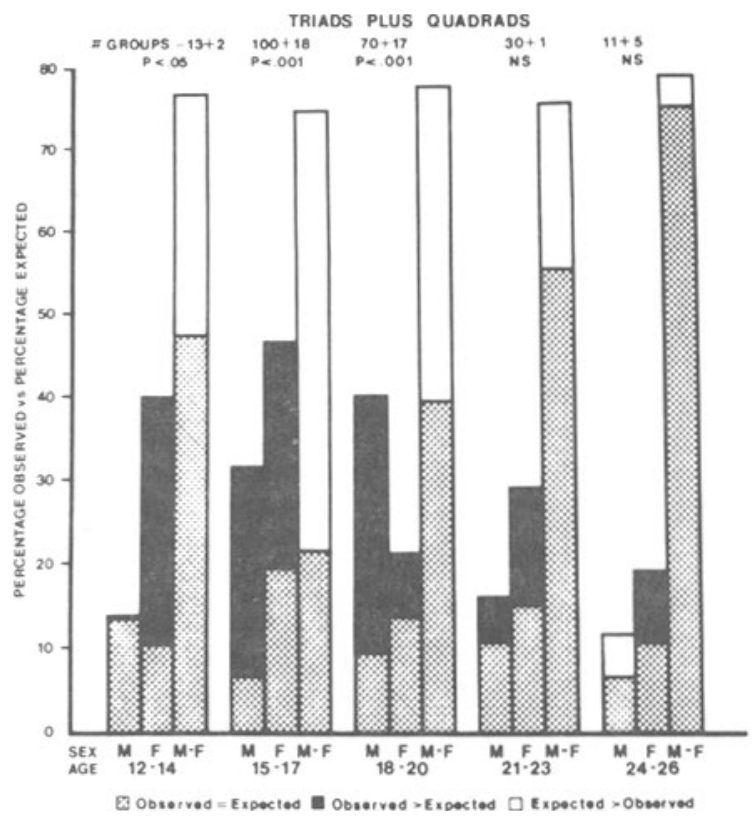

Figure 3. Triads and quadrads: Percentage of male, female, and mixed-sex groups of three to four individuals (e.g., $13+2=15$, triads and quadrads) observed in public vs. percentage expected, based on a binomial distribution, for five age categories. The focal category is subadult (18- to 20-year-olds), where a greater number than expected same-sex male groups are seen than either all-female or mixed-sex groups. Statistical significance using chi square is indicated by a probability statement (e.g., $p<.001)$; NS = not significant.
Figure 3 shows the comparisons relevant to the hypothesis of the study, those for groups of three or four persons. It is evident from the figure that male groups (18- to 20-year-olds) of more than two members were seen with much greater frequency than female groups of comparable ages $\left[\chi^{2}(8)=105.86, p<.001\right]$. This finding was further emphasized by the fact that while the overrepresentation of groups of three and four males increased from ages 15 years to age 20 years, the differential for the same-size female groups decreased.

\section{DISCUSSION}

The results of this study suggest that subgroup status for human subadult males is a viable concept. The hypothesis, which was potentially refutable, appears to have been confirmed by the demographic method of looking at relatively conservative behaviors, that is, how subjects group themselves by age and sex in public. It also appears that the method successfully isolated a phenomenon for further study. In general, the present study provides objective data on differences that "everyone already knows," as well as some that may not be so clearly a part of the conventional wisdom.

Questions may now be addressed as to why subadult males group together. A strong same-sex peer orientation is evident in the dyadic data (Figure 2) for both female and male juveniles 15-17 years old. The prevalence of subadult male groups of three or more members is not simply a function of the sex ratio in this age range, as in total numbers (singletons, dyads, triads, etc.) there were more female $(\mathrm{N}=1,269$, or $52.6 \%$ compared with $53.2 \%$ for the county from census data) than male $(\mathrm{N}=1,143)$ 18- to 20-year-olds observed.

It is possible, as has been suggested for other species of primates (DeVore, 1971), that, although human subadult males are sexually mature, they are neither physically nor experientially developed sufficiently to compete with older males for either females or essential resources of their society. Females 1820 years old may be a limiting factor (Trivers, 1972) if they prefer older males who are likely to control more resources. An attempt to account for the findings in terms of differing maturational rates, with males merely trailing females by several years, is not supported in a comparison of male groups aged 18-20 years with female groups aged 15-17 years. If males showed a simple developmental lag equivalent to the national age difference at marriage, namely, males 2.4 years older (Presser, 1975), the groupings of males and females of these two age categories should be roughly mirror images of each other in Figure 3, which they are not.

Reasons for the existence of human subadult male groups can only be speculative at this point. It could be that at 18-20 years of age, pairs of individuals, be they male, female, or mixed-sex dyads, represent an already accomplished transition to adulthood. Perhaps the "extra" individual reflects and, therefore, conveys a message of "availability." Consistent with this view, Konner (1976), in a discussion of the selective advantages of cross-age groupings among immature individuals in huntergatherer and nonhuman primate societies, contends that only the older adolescent males should be selected to form same-age/ same-sex peer groups. This prediction is based largely on the fact that this group benefits least from cross-age groups, as, for example, having little need for practicing alloparental behavior. In urban societies, subadult males may in fact be practicing to become adult males (by testing their abilities against males of similar ages) while waiting for an opportunity to pair with a female. That subadult males are seen in groups of three to four in shopping malls at all may indicate a "spillover" of an even greater tendency to band together in less centralized locations (i.e., literally peripheral males).

Although in many primate species maturing males often 
depart their natal group to form bachelor groups, this phenomenon is also common to a wider range of animals. Among the possible explanations proffered are that they are driven out of the group as competitors of dominant males, that they serve as buffers to predation, and that they are on the way to other groups as a means of obtaining diversity in the gene pool. The adaptive mechanisms involved in adolescent male subgroups may be applied as well to the elephant seal (Le Bouef, 1974), Gila topminnow (Constanz, 1975), red-winged blackbird (Wittenberger, 1976), sparrows (Smith, 1978), and scorpion hanging flies (Thornhill, 1976). The present findings attempted to extend the observations to humans.

\section{REFERENCES}

Chive rs, D. J. Spatial relations within the siamang family group. In J. Biegert \& W. Leutenegger (Eds.), Proceedings of the Third International Congress on Primatology (Zurich) (Vol. 3). Basel, N.Y: S. Karger, 1971.

Constanz, G. D. Behavioral ecology of mating in the male Gila topminnow, Pecciliopsis occidentalis (Cyprinodontıformes: Poeciliidae). Ecology, 1975, 56, 966-973.

Cohen, J. E. Casual groups of monkeys and men. Cambridge: Harvard University Press, 1971.

Coon, C. S. The hunting peoples. Boston: Little, Brown, 1971.

DeVore, I. The evolution of human society. In J. F. Eisenberg, W. S. Dillon, \& S. D. Ripley (Eds.), Man and beast: Comparative social behavior. Washington, D.C: Smithsonian Institution Press, 1971.

Hall, K. R. L., \& DeVore, I. Baboon social behavior. In I. DeVore (Ed.), Primate behavior. New York: Holt, Rinehart, \& Winston, 1965.

Harcourt, A. H., Steward, K. J., \& Fossey, D. Male emigration and female transfer in wild mountain gorilla. Nature, 1976, 263, 226-227.

HRDY, S. B. The langurs of Abu: Female and male strategies of reproduction. Cambridge: Harvard University Press, 1977.

JAY, P. The common langur of North India. In I. DeVore (Ed.), Primate behavior. New York: Holt, Rinehart, \& Winston, 1965.
Kon, I. S., \& Losenkov, V. A. [Friendship in adolescence: Values and behavior] (C. De Lissovoy \& V. De Lissovoy, trans.). Journal of Marriage and the Family, 1978, 40, 143-155.

KonNER, M. J. Relations among infants and juveniles in comparative perspective. Social Science Information, 1976, 15, $371-402$.

Kummer, H. Primate societies. Group techniques of ecological adaptation. In W. Goldschmidt (Ed.), Worlds of Man, Studies in Cultural Ecology. Chicago: Aldine, 1971.

LATANÉ, B., \& LiANE, D. Sex and affiliation in college cafeterias. Personality and Social Psychology Bulletin, 1977, 3, 571-574.

LEBouef, B. J. Male-male competition and reproductive success in elephant seals. American Zoologist, 1974, 14, 163-176.

MaccoBy, E. E., \& J ACKLIN, C. N. The psychology of sex differences. Stanford, Calif: Stanford University Press, 1974.

Presser, H. B. Age differences between spouses: Trends, patterns, and social implications. American Behavioral Scientist, 1975, 19, 190-205.

Schalle R, G. B. The mountain gorilla: Ecology and behavior. Chicago: University of Chicago Press, 1963.

Sмiтн, S. The "underworld" in a territorial sparrow: An adaptive strategy for floaters. American Naturalist, 1978, 112, 572-582.

SugiYama, Y., \& OHSAWA, T. [Population dynamics of Japanese macaques to Ryozenyama, Suzuka Mountains, 1. General review] (in Japanese). Japanese Journal of Ecology, 1974, 24, 50-59.

Thornhill, R. Sexual selection and nuptial feeding behavior in Bittacus apicalis (Insecta: Mecoptera). American Naturalist, 1976, 110, 529-548.

Tiger, L. Men in groups. New York: Random House, 1969.

Trivers, R. L. Parental investment and sexual selection. In B. Campbell (Ed.), Sexual selection and the descent of man 18711971. Chicago: Aldine, 1972.

WitTENBERGER, J. The ecological factors selecting for polygyny in altricial birds. American Naturalist, 1976, 110, 779-799.

(Received for publication February 18, 1980.) 